\title{
Association of SYNTAX Score with PATIMA Index, Carotid Intima- and Extra- Media Thicknesses
}

\author{
(1) Mehmet Cosgun1, (1) Zeliha Cosgun², () Yılmaz Güneş1, (1) İsa Sincer1, (1) Emrah Erdal1, \\ (1) Aslı Kurtar Mansıroğlu1, (1) Mehmet İnanır1
}

${ }^{1}$ Bolu Abant İzzet Baysal University Faculty of Medicine, Department of Cardiology, Bolu, Turkey
${ }^{2}$ Bolu Abant İzzet Baysal University Faculty of Medicine, Department of Radiology, Bolu, Turkey

\section{Abstract}

Objectives: Several risk scoring systems have been validated for cardiovascular risk prediction and prognosis. Periarterial adipose tissue intima media adventitia (PATIMA) index combining carotid intima media thickness (CIMT), carotid extra media thickness (CEMT), cardiac epicardial fat thickness (EFT), and body mass index (BMI) are related to coronary artery disease (CAD).

Materials and Methods: One-hundred-twenty-four patients were categorized as low synergy between percutaneous coronary intervention with taxus and cardiac surgery (SYNTAX) $(<22)(n=84)$ or high SYNTAX $(\geq 22)(n=40)$ score groups. Association of PATIMA index and its components with SYNTAX score were analyzed.

Results: CIMT, CEMT, BMI, EFT, and PATIMA index were not significantly different between groups. SYNTAX score was not significantly correlated with traditional CVS risk factors (diabetes, hypertension, hyperlipidemia, smoking, age). There was a significant correlation between the PATIMA index and age $(r=0.308, p=0.001)$ but not with other risk factors. Age was significantly correlated with CIMT $(r=0.289, p=0.001)$ and EFT $(r=0.208, p=0.02)$ but not with CEMT ( $r=0.091$, $\mathrm{p}=0.313)$. There was a significant correlation between CIMT and CEMT $(\mathrm{r}=0.414, \mathrm{p}<0.001)$ and between CIMT and EFT $(\mathrm{r}=0.267, \mathrm{p}=0.004)$.

Conclusion: We have found that the recently described PATIMA index and its components, CIMT, CEMT, and EFT are not associated with the severity of CAD assessed by the SYNTAX score. Furthermore, they have not correlated with classical risk factors apart from age.

Keywords: Carotid extra-media thickness, carotid intima-media thickness, coronary artery disease, PATIMA index, SYNTAX score Address for Correspondence: Mehmet Cosgun, Bolu Abant İzzet Baysal University, Department of Cardiology, Bolu, Turkey
e-mail: coskun44@gmail.com ORCID: orcid.org/0000-0002-6965-7444

Received: 31.01.2021 Accepted: 23.02.2021

Cite this article as: Cosgun M, Cosgun Z, Güneş Y, Sincer İ, Erdal E, Kurtar Mansıroğlu A, İnanır M. Association of SYNTAX Score with PATIMA Index, Carotid Intima- and Extra- Media Thicknesses. EJCM 2021;9(1):53-60.

DOI: 10.32596/ejcm.galenos.2021-01-09

${ }^{\circ}$ Copyright 2021 by Heart and Health Foundation of Turkey (TÜSAV) / E Journal of Cardiovascular Medicine published by Galenos Publishing House. 


\section{Introduction}

Strong correlation has been reported between the extent of carotid and coronary atherosclerosis ${ }^{(1,2)}$. Cardiovascular (CVS) risk prediction is an important goal in daily medical practice. Several risk scoring systems have been validated for CVS prognosis ${ }^{(3-5)}$. These systems usually use common risk factors and lack individual characteristics. Therefore, the results are inconclusive.

To improve predictive power of the risk score systems, several ultrasound-based indices have been suggested for the assessment of prognosis of atherosclerosis in addition to major clinical CVS risk factors. Carotid artery intima-media thickness (CIMT) is used for the early risk prediction of atherosclerosis, ischemic stroke, and myocardial infarction ${ }^{(6)}$. Few studies used common carotid artery extra-media thickness (CEMT) and reported its associations with CVS risk factors some of which were independent of $\mathrm{CIMT}^{(7)}$.

Recently, a new index called periarterial adipose tissue intima media adventitia (PATIMA) is a combination of several arterial wall and adipose tissue indices [CIMT and CEMT, cardiac epicardial fat thickness (EFT) and body mass index (BMI)] predicting the atheroscleoris and coronary artery disease (CAD) in different aspects. It has been reported that PATIMA index and CEMT are associated with the severity and also the presence of coronary artery disease ${ }^{(8)}$. However, the data are limited.

The synergy between percutaneous coronary intervention with taxus and cardiac surgery (SYNTAX) score (SS) is an angiography-based scoring system that evaluates the characteristics of the obstructive coronary lesions ${ }^{(9)}$. In the literature, it has been reported that there is a strong association between SS and cardiac complications after angiographic revascularization treatment in CAD patients. It has also been reported that there is a strong association between CIMT and $\mathrm{SS}^{(9-11)}$.

The aim of the study was to investigate the association between PATIMA index and the presence and the severity of CAD determined based on the SYNTAX scoring system in patients with high and very-high risk.

\section{Materials and Methods}

This study was prospectively designed, approved by the Local Ethics Committee of Bolu Abant İzzet Baysal University Clinical Researches Ethics Committee (reference no: 2019/26, date: 30.01.2019), and conducted according to the Helsinki Declaration between January and December 2019. A written and verbal informed consent was obtained from each subject. One hundred twenty-four consecutive patients undergoing coronary angiography for typical anginal symptoms or other noninvasive tests suggesting stable CAD in the university hospital's cardiology department, who had had at least single vessel CAD with $\geq 50 \%$ stenosis, were enrolled in the study.

Having a previous history of coronary, carotid or peripheral artery atherosclerosis, myocardial infarction, and moderate to severe heart valve disease, heart failure, significant renal failure, severe liver dysfunction and poor ultrasound image quality were determined as exclusion criteria.

Two experienced cardiologists analyzed the angiographic data of the patients blindly. Each coronary lesion causing a $\geq 50 \%$ diameter stenosis was scored based on the angiogram and using the SS algorithm, and these scores were combined to determine the total SS and the patients were grouped as low SS $(<22)$ or high SS $(\geq 22)$ groups $^{(12)}$.

Hypertension (HT) was determined in case of prior diagnosis or systolic blood pressure (SBP) $>140 \mathrm{mmHg}$ and/or diastolic blood pressure $>90 \mathrm{mmHg}$ in follow up. Following plasma lipid levels were determined as dyslipidemia [total cholesterol higher than $190 \mathrm{mg} / \mathrm{dL}$, low-density lipoprotein cholesterol higher than $115 \mathrm{mg} /$ $\mathrm{dL}$, triglycerides higher than $150 \mathrm{mg} / \mathrm{dL}$, high-density lipoprotein (HDL) cholesterol higher than $40 \mathrm{mg} / \mathrm{dL}$ in men and $<50 \mathrm{mg} / \mathrm{dL}$ in women $]^{(13)}$. Patients with plasma fasting glucose level $>126 \mathrm{mg} / \mathrm{dL}$ and $\mathrm{HbA} 1 \mathrm{c}$ level $>6.5 \%$ were diagnosed as diabetes mellitus (DM). In case 
of having doubt for the diagnosis of DM, having second hour post-load plasma glucose level $>200 \mathrm{mg} / \mathrm{dL}$ was defined as $\mathrm{DM}^{(14,15)}$. The presence of CAD in a first-degree relative of a male younger than 55 years or a first-degree relative of a female younger than 65 years was defined as a family history of $\mathrm{CAD}^{(16,17)}$.

\section{Ultrasonographic Measurements}

The electrocardiography-based ultrasonographic examination of bilateral carotid arteries was performed using high-resolution ultrasound (GE Healthcare, M4SRS, Tokyo, Hino-Shi, Japan) with a $7.5 \mathrm{MHz}$ linear transducer. The measurement of each carotid arteries was repeated three times and the mean values were used for analysis. All ultrasonographic measurements were performed by the same experienced physician who was blinded to the study. All the ultrasonographic images were recorded and measured by an experienced cardiologist blinded to the study, using constant settings. For each parameter, intra-observer variability was determined by comparing data of the same physician at two different measurement sessions. Intra-observer variabilities of measurements were assessed by the method which was defined by Bland and Altman ${ }^{(18)}$.

\section{Carotid Intima-media Thickness}

Both common carotid arteries of the participants were longitudinally scanned. Images obtained from the distal part of the common carotid artery, $1-2 \mathrm{~cm}$ proximal to the carotid bulb, were used for evaluation. The two hyperechogenic lines on the arterial wall were determined as the intima and media lines. The distance from these two hyper-echogenic lines was used for the measurements of carotid intima-media thickness (CIMT). Intra-observer variability for CIMT measurement was $3.6 \%$.

\section{Carotid Extra-media Thickness}

Carotid extra-media thickness (CEMT) incapsulates outer layer of the arterial wall, the adventitia layer, interstitial tissue, and perivascular adipose tissue ${ }^{(7)}$. The distance between the border of carotid media-adventitia, at approximately 1 to $1.5 \mathrm{~cm}$ proximal to the carotid bulb, and the wall of the jugular vein. The measurements were taken at end-diastole. Among ten patients, CEMT was measurable only in one carotid artery and these unilateral measurements were included in the study. CEMT could not be measured in four patients due to inadequate image quality to define CEMT border in either carotid arteries. Intra-observer variability for CEMT measurement was $2.7 \%$.

\section{Epicardial Fat Thickness}

The 4-Mhz transducer of Vivid S5 N (GE Vingmed, N-3191 Horten-Norway) was used to perform echocardiographic procedures. A single blind cardiologist took all echocardiographic images. The mean value of the three cardiac cycles was used. EFT was noted as an echofree or hyperechoic area between the epicardium and the visceral layer of the pericardium and it reflected visceral adipose tissue $^{(19)}$. The assessment of EFT thickness was performed from the parasternal long- and short axis views of the free wall of the right ventricle. The measurement was made at the level of the aortic annulus perpendicular to the free wall of the right ventricle. The measurements of maximum values were made at the end of diastole. The intra-observer variation for EFT was $4.3 \%$.

\section{PATIMA Index}

PATIMA index was calculated as (CEMT / BMI x 35) + CIMT + (EFT x 60), which was described by Haberka et al. ${ }^{(8)}$

\section{Statistical Analysis}

SPSS (version 16; SPSS Inc. Chicago, Illinois) software was used to perform statistical analysis. Data were presented as mean \pm standard deviation and nonparametric data were expressed as number and percentages of the total. The Kolmogorov-Smirnov test was used to test whether the data were distributed normally. Data between the groups were compared with the chi-square test for qualitative variables and the Student's t-test or MannWhitney $U$ test for quantitative variables. The correlation 
between atherosclerosis markers was evaluated using the Spearman correlation test. A p-value below 0.05 was considered as significant.

\section{Results}

A total of 124 CAD patients were included in the study. There were 84 low- and 40 high-SS patients. There was no significant difference between low- and high-SS patients in terms of baseline clinical characteristics. CIMT, CEMT, BMI, EFT, and PATIMA index were also not significantly different (Table 1).

SYNTAX score was not significantly correlated with classical CVS risk factors. A significant correlation was found between PATIMA index and age but not with other CVS risk factors (Table 2). Age was significantly correlated with CIMT $(r=0.289, \mathrm{p}=0.001)$ and EFT $(\mathrm{r}=0.208, \mathrm{p}=0.02)$ but not with CEMT $(\mathrm{r}=0.091, \mathrm{p}=0.313)$. There was a significant correlation between CIMT and CEMT $(r=0.414, p<0.001)$ and between CIMT and EFT $(\mathrm{r}=0.267, \mathrm{p}=0.004)$.

Table 1. Comparison of baseline clinical characteristics and ultrasound indices between the groups

\begin{tabular}{|c|c|c|c|}
\hline & $\begin{array}{l}\text { SYNTAX score <22 } \\
\text { (group 1) }(n=84)\end{array}$ & $\begin{array}{l}\text { SYNTAX score } \geq 22 \\
\text { (group } 2)(n=40)\end{array}$ & $p$-value \\
\hline Age (years), mean \pm SD & $63.8 \pm 10.9$ & $64.6 \pm 9.3$ & 0.670 \\
\hline Sex (male) & $75 \%(63)$ & $82.5 \%(33)$ & 0.491 \\
\hline HT & $60.7 \%(51)$ & $52.5 \%(21)$ & 0.439 \\
\hline DM & $36.9 \%(31)$ & $45 \%(18)$ & 0.435 \\
\hline HL & $13.1 \%(11)$ & $10 \%(4)$ & 0.772 \\
\hline Smoking & $22.6 \%(19)$ & $27.5 \%(11)$ & 0.625 \\
\hline$E F,(\%)$ & $57.5 \pm 8.3$ & $54.9 \pm 8.6$ & 0.018 \\
\hline CEMT, $(\mu \mathrm{m})$ & $700(600-800)$ & $700(600-800)$ & 0.750 \\
\hline BMI, $\left(\mathbf{k g} / \mathbf{m}^{2}\right)$ & $28.69 \pm 4.43$ & $28.85 \pm 4.73$ & 0.775 \\
\hline
\end{tabular}

\section{Discussion}

We have found that recently described PATIMA index and its components, CIMT, CEMT, and EFT are not associated with CAD severity calculated by SS. Furthermore, they are not correlated with classical CAD risk factors [DM, HT, smoking, Hyperlipidemia (HL)] apart from age.

The SS consists of a combine validated angiographic evaluation to classify the coronary lesions in terms of the number, functional impact, and complexity of them ${ }^{(20)}$. The SS is essentially recommended for decision making for coronary angiography rather than prediction for functional outcome of the patients. However, its prognostic utility has been validated in different settings, including patients with three-vessel or left-main CAD undergoing either percutaneous coronary intervention or coronary bypass surgery ${ }^{(21-24)}$. The SS has also been used to assess the relationship between carotid ultrasonographic findings and CAD severity ${ }^{(9-11)}$. Association of CIMT with CAD severity is controversial. Although several studies have reported that there is an association between CIMT and

\footnotetext{
Cosgun et al. PATIMA Index in Coronary Artery Disease
} 
the presence and severity of $\mathrm{CAD}^{(9,25)}$, Saedi et al. ${ }^{(26)}$ found no significant correlation between CIMT and SS. Ikeda et al. ${ }^{(10)}$ studied CIMT and SS in 501 patients and reported a significant correlation between the CIMT and the SS and similar to our population, majority of patients $(84.8 \%)$ had a low SS value $(<22)$. However, the mean CIMT value in their study was higher than that in our study $(0.9 \mathrm{~mm}$ vs. $0.7 \mathrm{~mm}$ ). Lack of association between CIMT and SS in our study may be partially explained with relatively low mean CIMT value $(0.7 \mathrm{~mm})$ compared to previous studies. However, Costanzo et al. ${ }^{(27)}$ reported high prevalence of carotid lesion in patients with complex CAD with relatively high average CIMT $(1.15 \mathrm{~mm})$ but similar to our findings, SS was not correlated with the presence of carotid disease in their multivessel CAD patients.

Different from a well-known CIMT, CEMT is an ultrasound index of outermost layer of distal segments of the common carotid artery and jugular vein ${ }^{(19,28,29)}$. It has been shown that arterial adventitia has undergone thickening and remodeling in response to experimental
HT and $\mathrm{HL}^{(30)}$. However, assessment of this outer part of arterial wall has not gained popularity. Lefferts et al. ${ }^{(31)}$ found that CEMT, but not CIMT, was significantly associated with carotid stiffness in young, apparently healthy men. They suggested that visceral adiposity and carotid hemodynamics detrimentally affect CEMT and in turn, impact carotid wall stiffness. CEMT was also found to be related to metabolic syndrome and adiposity ${ }^{(28)}$. CIMT and CEMT were shown to be increased in $\mathrm{HT}^{(32)}$. Skilton et al. ${ }^{(7)}$ found that CEMT was increased in DM and HL. They reported that there was a negative association between HDL and CIMT, a J-shaped association between SBP and CIMT, and a positive association between DM and CIMT. Saedi et al. ${ }^{(26)}$ reported that the presence of HT and DM may be related to increased CIMT. However, in the present study, we could not find such an association of CIMT and CEMT with CVS risk factors including DM and $\mathrm{HL}$ in patients with documented CAD. Supporting our findings, in a retrospective study, Cai at al. ${ }^{(33)}$ reported that there was an association between CIMT and CVS events

Table 2. Correlation Between SYNTAX Score and PATIMA Index and The Clinical and Ultrasound Indices in Study Subjects

\begin{tabular}{|c|c|c|}
\hline Variables & SYNTAX score & PATIMA index \\
\hline Age & $\begin{array}{l}r=0.059 \\
p=0.512\end{array}$ & $\begin{array}{l}r=0.308 \\
p=0.001\end{array}$ \\
\hline HT & $\begin{array}{l}r=0.048 \\
p=0.597\end{array}$ & $\begin{array}{l}r=0.010 \\
p=0.910\end{array}$ \\
\hline DM & $\begin{array}{l}r=0.039 \\
p=0.667\end{array}$ & $\begin{array}{l}r=0.015 \\
p=0.873\end{array}$ \\
\hline Smoke & $\begin{array}{l}r=0.053 \\
p=0.560\end{array}$ & $\begin{array}{l}r=0.118 \\
p=0.193\end{array}$ \\
\hline EFT & $\begin{array}{l}r=0.155 \\
p=0.088\end{array}$ & $\begin{array}{l}r=0.479 \\
p<0.001\end{array}$ \\
\hline CEMT & $\begin{array}{l}r=0.040 \\
p=0.662\end{array}$ & $\begin{array}{l}r=0.716 \\
p<0.001\end{array}$ \\
\hline BMI & $\begin{array}{l}r=0.001 \\
p=0.992\end{array}$ & $\begin{array}{l}r=0.255 \\
p=0.004\end{array}$ \\
\hline PATIMA index & $\begin{array}{l}r=0.039 \\
p=0.665\end{array}$ & - \\
\hline
\end{tabular}


in adults having the risk of CAD and reported that unlike CIMT, there was no significant association between CEMT and CVS events in high-risk adults. Different results about the association of other CVS risk factors with ultrasound indexes may depend on the population studied but age is constant. Aging itself has an important role in the pathogenesis of atherosclerosis through physiological degenerative CVS changes. Of the CVS risk factors, age has the strongest independent association with atherosclerosis possibly combining the role of other established risk factors and aging itself.

Haberka et al. ${ }^{(8)}$ have combined CEMT and CIMT with periarterial fat indices and proposed PATIMA index as a combined reflection of these well-known and relatively new CVS risk predictors. They reported that PATIMA was related to the presence and as well as the severity of CAD. Furthermore, higher PATIMA indices were suggested to predict more complex CAD comparing with singleultrasound variables and clinically assessed risk factors ${ }^{(34)}$. Recently, Haberka et al. ${ }^{(35)}$ have reported that carotid vascular indices (CIMT, CEMT, and PATIMA index), may provide to predict the indication of coronary revascularization in high or very high-risk CAD patients, although clinical evaluation and the presence of CVS risk factors did not have provided a predictive value. In contrast to the reports of Haberka et al. ${ }^{(36)}$, in our study, however, no significant association was found between PATIMA index and the severity of CAD assessed by SS. The design of our study is cross-sectional, and the number of patients is relatively small. Therefore, the relationship between ultrasound indexes and their combined outcomePATIMA index with the severity of CAD can be limited due to individual variations of the studied indexes. Such that some parameters that influence the SS may not be related to atherosclerosis burden like vessel tortuosity and bifurcation lesion angle.

\section{Study Limitations}

Measurements of CEMT, EFT and to a lesser extent CIMT require training and experience to obtain optimal image ${ }^{(28,29,36)}$. However, the measurements were performed by an experienced observer and patients with inadequate image quality were excluded. Relatively small number of study patients may be a reason for our unavailability to find an association between PATIMA and CEMT with severity of CAD. Due to lack of a control group having normal coronary arteries, we were not able to speculate about predictive value of studied indices for the presence of CAD.

\section{Conclusion}

In this single-center study, on the contrary to previous few studies, we found that PATIMA index and its components, CIMT, CEMT and EFT were not associated with CAD severity calculated by SS. Larger studies are required to determine the association between these parameters and severity of CAD.

\section{Ethics}

Ethics Committee Approval: This study was approved by Bolu Abant İzzet Baysal University Clinical Researches Ethics Committee (ref. no: 2019/26, date: 30.01.2019).

Informed Consent: Informed consents were obtained from all individual participants included in the study.

Peer-review: Externally peer-reviewed.

\section{Author Contributions}

Concept: M.C., Z.C., Design: M.C., Z.C., Y.G., Data Collection/Processing: M.C., E.E., A.K.M., M.İ., Analysis and/or Interpretation: M.C., Z.C., İ.S., Literature Review: M.C., Y.G., Drafting/Writing: M.C., E.E., Y.G., Critical Review: M.C., Y.G.

Conflict of Interest: Authors declared no conflict of interest.

Financial Disclosure: None declared by the authors.

\section{References}

1. Mitchell Jr, Schwartz Cj. Relationship between arterial disease in different sites. A study of the aorta and coronary, carotid, and iliac arteries. Br Med J 1962;1:1293-301. 
2. Demirel ME, Donmez I, Ucaroglu ER, Yuksel A. Acute coronary syndromes and diagnostic methods. Med Res Innov 2019;3:1-8.

3. Feinleib M, Kannel WB, Garrison RJ, McNamara PM, Castelli WP. The Framingham Offspring Study. Design and preliminary data. Prev Med 1975;4:518-25.

4. Conroy RM, Pyörälä K, Fitzgerald AP, et al. Estimation of ten-year risk of fatal cardiovascular disease in Europe: the SCORE project. Eur Heart $\mathrm{J}$ 2003;24:987-1003.

5. Assmann G, Cullen P, Schulte H. Simple scoring scheme for calculating the risk of acute coronary events based on the 10-year follow-up of the prospective cardiovascular Münster (PROCAM) study. Circulation 2002;105:310-5.

6. Alipour M, Masri D, Mofazzali A, Chitsazan M. Carotid artery intimamedia thickness in patients undergoing coronary artery bypass graft surgery. Arch Cardiovasc Imaging 2013;1:27-31.

7. Skilton MR, Sérusclat A, Sethu AH, et al. Noninvasive measurement of carotid extra-media thickness: associations with cardiovascular risk factors and intima-media thickness. JACC Cardiovasc Imaging 2009;2:176-82.

8. Haberka M, Gąsior Z. A carotid extra-media thickness, PATIMA combined index and coronary artery disease: Comparison with well-established indexes of carotid artery and fat depots. Atherosclerosis 2015;243:307-13.

9. Korkmaz L, Bektas H, Korkmaz AA, et al. Increased carotid intimamedia thickness is associated with higher SYNTAX score. Angiology 2012;63:386-9.

10. Ikeda N, Kogame N, Iijima R, Nakamura M, Sugi K. Carotid artery intimamedia thickness and plaque score can predict the SYNTAX score. Eur Heart J 2012;33:113-9.

11. Ikeda N, Saba L, Molinari F, et al. Automated carotid intima-media thickness and its link for prediction of SYNTAX score in Japanese coronary artery disease patients. Int Angiol 2013;32:339-48.

12. SYNTAX score calculator. Available at: http://www.SYNTAXscore.com. SYNTAX working-group. Accessed May 2013.

13. Perk J, De Backer G, Gohlke H, et al. European Guidelines on cardiovascular disease prevention in clinical practice (version 2012). The Fifth Joint Task Force of the European Society of Cardiology and Other Societies on Cardiovascular Disease Prevention in Clinical Practice (constituted by representatives of nine societies and by invited experts). Eur Heart $\mathrm{J}$ 2012;33:1635-701.

14. World Health Organization (WHO) Consultation, Definition and Diagnosis of Diabetes and Intermediate Hyperglycaemia, 2006; p. 1-50.

15. World Health Organization (WHO), Abbreviated Report of a WHO Consultation. Use of Glycated Hemoglobin (HbAlc) in the Diagnosis if Diabetes Mellitus, 2011. p.1-25.

16. British Cardiac Society; British Hypertension Society; Diabetes UK; HEART UK; Primary Care Cardiovascular Society; Stroke Association. JBS 2: Joint British Societies' guidelines on prevention of cardiovascular disease in clinical practice. Heart 2005;91:v1-52.

17. National Cholesterol Education Program (NCEP) Expert Panel on Detection, Evaluation, and Treatment of High Blood Cholesterol in Adults (Adult Treatment Panel III). Third Report of the National Cholesterol Education Program (NCEP) Expert Panel on Detection, Evaluation, and
Treatment of High Blood Cholesterol in Adults (Adult Treatment Panel III) final report. Circulation 2002;106:3143-421.

18. Bland JM, Altman DG. Statistical methods for assessing agreement between two methods of clinical measurement. Lancet 1986;1:307-10.

19. Iacobellis G, Assael F, Ribaudo MC, et al. Epicardial fat from echocardiography: a new method for visceral adipose tissue prediction. Obes Res 2003;11:304-10.

20. Sianos G, Morel MA, Kappetein AP, et al. The SYNTAX Score: an angiographic tool grading the complexity of coronary artery disease. EuroIntervention 2005;1:219-27.

21. Valgimigli M, Serruys PW, Tsuchida K, et al. Cyphering the complexity of coronary artery disease using the syntax score to predict clinical outcome in patients with three-vessel lumen obstruction undergoing percutaneous coronary intervention. Am J Cardiol 2007;99:1072-81.

22. Lemesle G, Bonello L, de Labriolle A, et al. Prognostic value of the Syntax score in patients undergoing coronary artery bypass grafting for threevessel coronary artery disease. Catheter Cardiovasc Interv 2009;73:612-7.

23. Capodanno D, Di Salvo ME, Cincotta G, Miano M, Tamburino C, Tamburino C. Usefulness of the SYNTAX score for predicting clinical outcome after percutaneous coronary intervention of unprotected left main coronary artery disease. Circ Cardiovasc Interv 2009;2:302-8.

24. Birim O, van Gameren M, Bogers AJ, Serruys PW, Mohr FW, Kappetein AP. Complexity of coronary vasculature predicts outcome of surgery for left main disease. Ann Thorac Surg 2009;87:1097-104.

25. Kablak-Ziembicka A, Tracz W, Przewlocki T, Pieniazek P, Sokolowski A, Konieczynska M. Association of increased carotid intima-media thickness with the extent of coronary artery disease. Heart 2004;90:1286-90.

26. Saedi S, Ghadrdoost B, Pouraliakbar H, Zahedmehr A, Jebelli A. The association between increased carotid intima-media thickness and SYNTAX Score in coronary artery disease: A single center study. Indian Heart J 2018;70:627-9.

27. Costanzo L, Campisano MB, Capodanno D, et al. The SYNTAX score does not predict presence of carotid disease in a multivessel coronary disease population. Catheter Cardiovasc Interv 2014;83:1169-75.

28. Haberka M, Gąsior Z. Carotid extra-media thickness in obesity and metabolic syndrome: a novel index of perivascular adipose tissue: extramedia thickness in obesity and metabolic syndrome. Atherosclerosis 2015;239:169-77.

29. Falk E, Thim T, Kristensen IB. Atherosclerotic plaque, adventitia, perivascular fat, and carotid imaging. JACC Cardiovasc Imaging 2009;2:183-6

30. Herrmann J, Samee S, Chade A, Rodriguez Porcel M, Lerman LO, Lerman A. Differential effect of experimental hypertension and hypercholesterolemia on adventitial remodeling. Arterioscler Thromb Vasc Biol 2005;25:447-53.

31. Lefferts WK, Sperry SD, Jorgensen RS, et al. Carotid stiffness, extramedia thickness and visceral adiposity in young adults. Atherosclerosis 2017;265:140-6

32. D'Amico F, Grasso R. Carotid intima-media and extra-media thickness in hypertensive elderly subjects. Journal of Hypertension 2015;33:497.

33. Cai TY, Magnussen C, Haluska B, et al. Carotid extra-medial thickness does not predict adverse cardiovascular outcomes in high-risk adults. Diabetes Metab 2016;42:200-3. 
34. Haberka M, Lelek M, Bochenek T, et al. Novel combined index of cardiometabolic risk related to periarterial fat improves the clinical prediction for coronary artery disease complexity. Atherosclerosis 2018;268:76-83.

35. Haberka M, Bałys M, Matla M, Kubicius A, Maciejewski Ł, Gąsior Z. Carotid artery stenosis and ultrasound vascular indexes predict the coronary revascularization in patients with high cardiovascular risk scheduled for coronary angiography. Kardiol Pol 2019;77:1028-33.

36. Haberka M, Sosnowski M, Zuziak-Pruska J, Gąsior Z. Extra-media thickness and epicardial fat: Comparison of a novel carotid artery ultrasound index and a well-established cardiac magnetic resonance fat quantification method. Nutr Metab Cardiovasc Dis 2015;25:763-70. 